\title{
Effect Factors of Benzene Adsorption and Degradation by Nano-TiO 2 Immobilized on Diatomite
}

\author{
Lijun Cheng, ${ }^{1}$ Yong Kang, ${ }^{1}$ and Guishui $\mathrm{Li}^{2}$ \\ ${ }^{1}$ School of Chemical Engineering and Technology, Tianjin University, Tianjin 300072, China \\ ${ }^{2}$ College of Mechanical Engineering, Tianjin University of Science and Technology, Tianjin 300222, China
}

Correspondence should be addressed to Yong Kang, ykang@eyou.com

Received 25 October 2012; Revised 11 November 2012; Accepted 26 November 2012

Academic Editor: Yong Yang

Copyright (C) 2012 Lijun Cheng et al. This is an open access article distributed under the Creative Commons Attribution License, which permits unrestricted use, distribution, and reproduction in any medium, provided the original work is properly cited.

\begin{abstract}
Difference between adsorption of benzene by diatomite and nano- $\mathrm{TiO}_{2}$ immobilized on diatomite was investigated. And effects of temperature, light intensity, relative humidity, and initial benzene concentration on adsorption and degradation of benzene by nano- $\mathrm{TiO}_{2}$ immobilized on diatomite were also studied. The experimental results showed that when initial benzene concentration was $2.2 \times 10^{-3} \mathrm{mg} \mathrm{L}^{-1}$, it could be degraded to below safe concentration $\left(1.1 \times 10^{-4} \mathrm{mg} \mathrm{L}^{-1}\right)$ after $50 \mathrm{~h}$ when temperature was $20^{\circ} \mathrm{C}$, but it just needed $30 \mathrm{~h}$ at $35^{\circ} \mathrm{C}$. When light intensity was $6750 \mathrm{Lx}$, it needed $30 \mathrm{~h}$ for benzene to be degraded to below safe concentration, but benzene could barely be degraded without light. When relative humidity was $50 \%$, benzene could be degraded to $1.0 \times 10^{-4} \mathrm{mg} \mathrm{L}^{-1}$ after $30 \mathrm{~h}$, while its concentration could be reduced to $7.0 \times 10^{-5} \mathrm{mg} \mathrm{L}^{-1}$ at the relative humidity of $80 \%$.
\end{abstract}

\section{Introduction}

Benzene, which primarily comes from coating, painting, adhesives, and other organic solvents inside buildings, has become one of the most toxic substances and has been identified as a kind of strong carcinogenic substance by Word Health Organization. So it is very important and meaningful to remove benzene in houses and workplaces considering human health.

At present, there are some methods employed to remove benzene such as microbial degradation $[1,2]$, adsorption [37], catalytic oxidation [8-14], and so forth, among which photocatalytic degradation of benzene by $\mathrm{TiO}_{2}$ has attracted wide attention [11-14]. This is because $\mathrm{TiO}_{2}$ can degrade many toxic substances under mild conditions and cannot cause secondary pollution [15-18], besides being quite easy to operate, making it become a simple way to remove poisonous gases indoors. But as nano-size $\mathrm{TiO}_{2}$ powder is inclined to aggregate to clusters and hard to be fixed, if being directly doped into coatings to paint walls or furnitures, it is very easy to fall off. So researchers have investigated many methods to fix $\mathrm{TiO}_{2}$ on certain supports, among which diatomite is just a good carrier. As there exists a lot of silicon hydroxyls and hydrogen bonds on the surface of diatomite, it can form strong force with $\mathrm{TiO}_{2}$, thus overcoming the difficulty of $\mathrm{TiO}_{2}$ fixing. In addition, nano$\mathrm{TiO}_{2}$ immobilized on diatomite combines both large specific area of diatomite and strong oxidation ability of $\mathrm{TiO}_{2}$, which shows broad prospect in green adornments.

Based on our previous work [19-21], nano- $\mathrm{TiO}_{2}$ immobilized on diatomite prepared by using $\mathrm{TiOSO}_{4}$ as raw material, urea as precipitator and diatomite as support was employed to degrade benzene in this work. To verify advantage of nano- $\mathrm{TiO}_{2}$ immobilized on diatomite, difference between adsorption of benzene by diatomite and nano$\mathrm{TiO}_{2}$ immobilized on diatomite was compared and effects of temperature, light intensity, relative humidity, and initial concentration of benzene on adsorption and degradation of benzene by nano- $\mathrm{TiO}_{2}$ immobilized on diatomite were also discussed.

\section{Experimental}

Diatomite and nano- $\mathrm{TiO}_{2}$ immobilized on diatomite were used as the adsorption and degradation materials, as discussed elsewhere [20]. Their morphology is shown in 


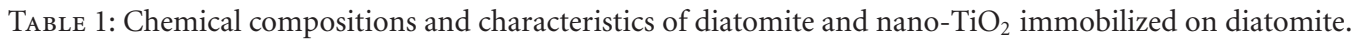

\begin{tabular}{|c|c|c|}
\hline & Diatomite & Nano- $\mathrm{TiO}_{2}$ immobilized on diatomite \\
\hline \multirow{2}{*}{ Chemical compositions } & Main: $\mathrm{SiO}_{2}$ & Main: $\mathrm{SiO}_{2} \mathrm{TiO}_{2}$ \\
\hline & $\begin{array}{l}\text { Other: } \mathrm{Al}_{2} \mathrm{O}_{3} \mathrm{Fe}_{2} \mathrm{O}_{3} \mathrm{CaO} \mathrm{MgO} \mathrm{K}_{2} \mathrm{O} \mathrm{Na} \mathrm{Na}_{2} \mathrm{O} \text { and } \\
\text { other organic substances }\end{array}$ & $\begin{array}{l}\text { Other: } \mathrm{Al}_{2} \mathrm{O}_{3} \mathrm{Fe}_{2} \mathrm{O}_{3} \mathrm{CaO} \mathrm{MgO} \mathrm{K} \mathrm{O} \mathrm{Na}_{2} \mathrm{O} \text { and other } \\
\text { organic substances }\end{array}$ \\
\hline Characteristics & $\begin{array}{l}\text { Grain size and specific area were } 10 \sim 100 \mu \mathrm{m} \text { and } \\
1.2995 \mathrm{~m}^{2} / \mathrm{g} \text {, respectively }\end{array}$ & $\begin{array}{l}\text { Crystalline phase of } \mathrm{TiO}_{2} \text { was anatase, grain size was } \\
150 \mathrm{~nm} \text { and cover percent was } 75 \%\end{array}$ \\
\hline
\end{tabular}

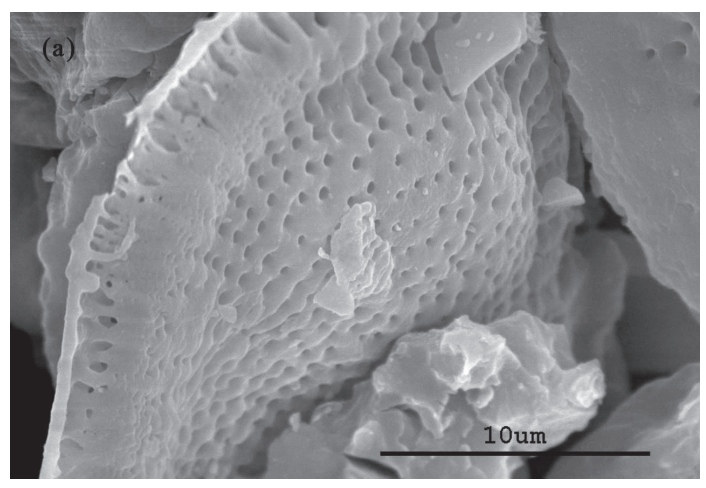

(a)

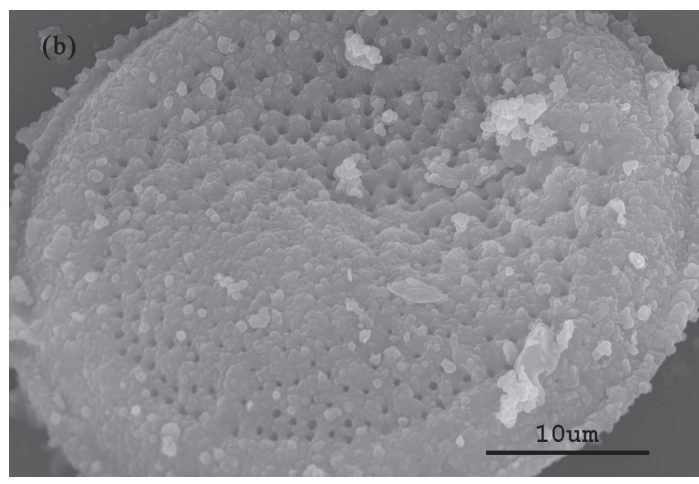

(b)

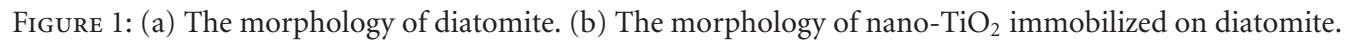

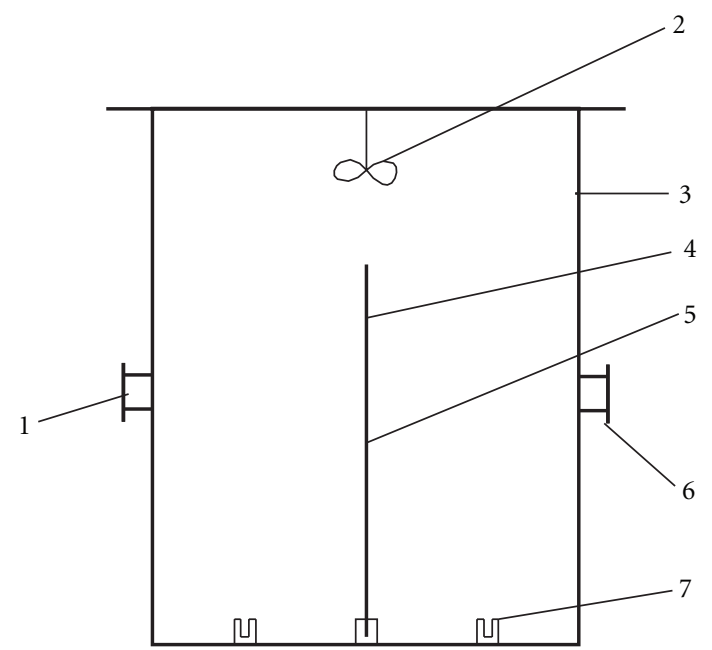

Figure 2: The innercircle reactor for degradating benzene (1sample connection, 2-fan, 3-shell, 4-glass plate, 5-nano- $\mathrm{TiO}_{2}$, 6injection port, 7-slot).

Figure 1. And their chemical compositions and characteristics are shown in Table 1. Benzene obtained by evaporating its standard solution (the concentration was $100 \mathrm{mg} \mathrm{L}^{-1}$ ) was used as the target degraded gas, initial concentration of which was $0.0022 \mathrm{mg} \mathrm{L}^{-1}$. Ground glass, the effective area of which was $0.08 \mathrm{~m}^{2}$, was used as the support of photocatalysts. The structure of the photocatalytic reactor (the volume was $5 \mathrm{~L}$ ) is shown in Figure 2.
Adsorption by reactor: before experiment, the reactor was cleaned, dried, and sealed. Then the standard solution of benzene was injected into it. When the solvent evaporated thoroughly, it was put into illumination incubator with temperature of $35^{\circ} \mathrm{C}$. During adsorption process, $1 \mathrm{~mL}$ gas was taken out from the reactor at regular intervals and analyzed by Gas Chromatography to determine the concentration of benzene.

Comparison of adsorption by diatomite and nano$\mathrm{TiO}_{2}$ immobilized on diatomite: nano- $\mathrm{TiO}_{2}$ immobilized on diatomite of $2 \mathrm{~g}$ was put into the reactor and benzene's standard solution of $0.29 \mathrm{~mL}$ was also injected into it. Then the reactor was put into illumination incubator with temperature of $35^{\circ} \mathrm{C}$ and 5 fluorescent lamps opened. Like the above experiment, $1 \mathrm{~mL}$ gas was taken out from the reactor at regular intervals and analyzed by gas chromatography to determine the concentration of benzene. When finished, the reactor was cleaned and dried, and experiment was repeated with diatomite of $2 \mathrm{~g}$ under the same conditions to compare the difference of these two materials.

Effect of reaction conditions on degradation of benzene by nano- $\mathrm{TiO}_{2}$ immobilized on diatomite: take the experiment about effect of temperature as example, nano- $\mathrm{TiO}_{2}$ immobilized on diatomite of $2 \mathrm{~g}$ was put into the reactor and benzene's standard solution of $0.11 \mathrm{~mL}$ was also injected into it. Then the reactor was put into illumination incubator with temperature of $35^{\circ} \mathrm{C}$ and 5 fluorescent lamps opened. Similarly, $1 \mathrm{~mL}$ gas was taken out from the reactor at regular intervals and analyzed by gas chromatography to determine the concentration of benzene. The process ended when the concentration of benzene decreased to below its safe 


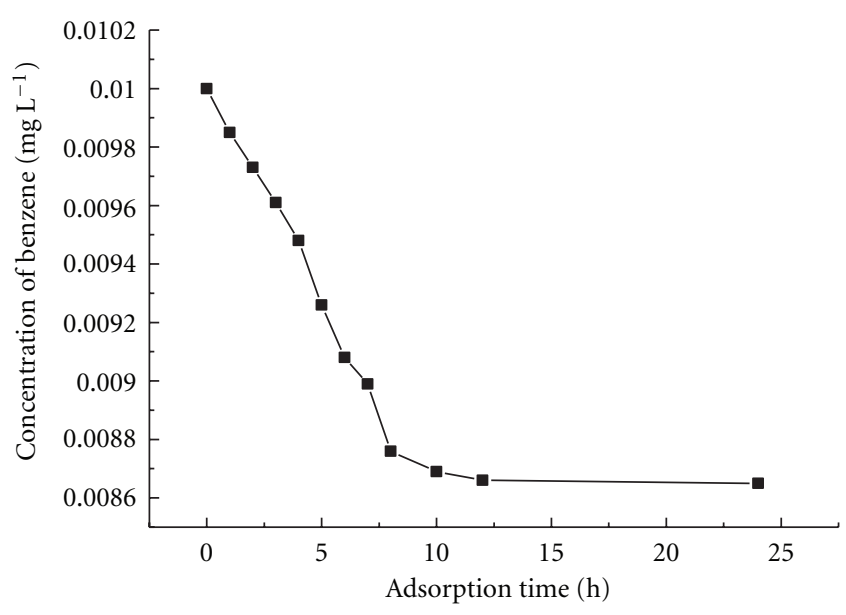

FIgURE 3: Curve of adsorption equilibrium by reactor.

concentration. Experiment was repeated at $20^{\circ} \mathrm{C}$ to study the effect of temperature on degradation of benzene.

\section{Results and Discussion}

3.1. Adsorption by Reactor. When benzene is injected into a closed reactor, some gas will be adsorbed to the wall of the reactor. Accordingly, the degradation ability of nano$\mathrm{TiO}_{2}$ immobilized on diatomite will be artificially increased if this part of adsorption capacity does not be excluded. In order to reduce this kind of error, the experiment about the adsorption of benzene by the reactor was conducted and the curve of adsorption equilibrium was obtained, as seen in Figure 3.

From Figure 3, it can be seen that the adsorption at the first $8 \mathrm{~h}$ was almost linear. The concentration of benzene reduced from $0.01 \mathrm{mg} \mathrm{L}^{-1}$ to $0.00866 \mathrm{mg} \mathrm{L}^{-1}$ after adsorption for $12 \mathrm{~h}$ and almost maintained unchanged until $24 \mathrm{~h}$, implying the saturated concentration of benzene for the reactor was $0.00134 \mathrm{mg} \mathrm{L}^{-1}$. To avoid relative error, in the following experiments, the real adsorbed concentration of benzene by nano- $\mathrm{TiO}_{2}$ was the concentration obtained by experiment minus $0.00134 \mathrm{mg} \mathrm{L}^{-1}$.

3.2. Comparison of Adsorption by Diatomite and $\mathrm{Nano}-\mathrm{TiO}_{2}$ Immobilized on Diatomite. The concentration changes of benzene adsorbed by diatomite and nano- $\mathrm{TiO}_{2}$ immobilized on diatomite under the same mass are shown in Figure 4.

It can be seen from Figure 4 that adsorption and degradation of benzene by different materials were quite different. Diatomite has strong adsorption capacity owing to its many holes, as seen in Figure 1(a). At the first $12 \mathrm{~h}$, the concentration of benzene decreased sharply. At this period, the adsorption rate of benzene on diatomite was much larger than the desorption rate. While at the later $12 \mathrm{~h}$, the slope of the curve greatly decreased and tended to become unchanged, which demonstrated that the adsorption rate of benzene on diatomite was almost equal to the desorption rate and the concentration of benzene kept

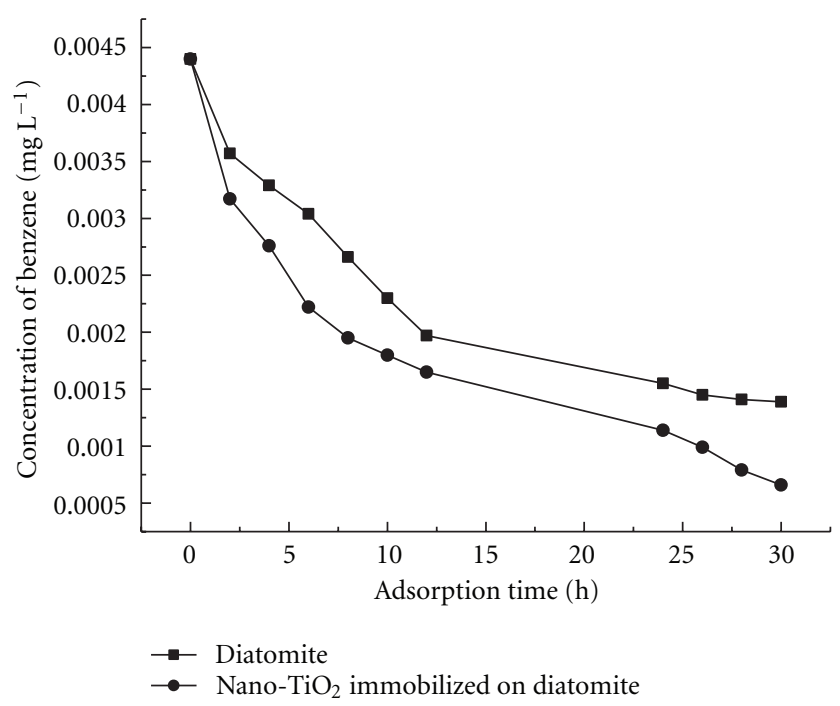

Figure 4: Comparison of adsorption between diatomite and nano$\mathrm{TiO}_{2}$ immobilized on diatomite.

steady. From the figure, it can be found that after adsorption by diatomite of $2 \mathrm{~g}$, the concentration of benzene reduced from $0.0044 \mathrm{mg} \mathrm{L}^{-1}$ to $0.00139 \mathrm{mg} \mathrm{L}^{-1}$.

While for the nano- $\mathrm{TiO}_{2}$ immobilized on diatomite, the adsorption rate at the first $12 \mathrm{~h}$ was greater than that of diatomite. This was because benzene was not only adsorbed to the diatomite through physical effect but also oxided to $\mathrm{CO}_{2}$ and $\mathrm{H}_{2} \mathrm{O}$ by light-generated holes on the surface of the nano- $\mathrm{TiO}_{2}$, which led to more adsorption of benzene on nano- $\mathrm{TiO}_{2}$ immobilized on diatomite than on diatomite alone. Moreover, the concentration of benzene still kept decreasing untill $30 \mathrm{~h}$, although the degradation rate was smaller than that of the first $12 \mathrm{~h}$. At this stage, desorption of benzene from the nano- $\mathrm{TiO}_{2}$ immobilized on diatomite gradually appeared, but the desorption rate was still smaller than the adsorption rate, so the concentration of benzene still kept reducing, indicating that the nano- $\mathrm{TiO}_{2}$ had lasting degradation effect on benzene.

3.3. Effect of Temperature on Adsorption and Degradation of Benzene by Nano-TiO ${ }_{2}$ Immobilized on Diatomite. The change tendencies of benzene's concentration under different temperature are shown in Figure 5.

It demonstrated that the degradation rate of benzene increased with the rise of reaction temperature. From the figure, it can be seen that when the temperature was $20^{\circ} \mathrm{C}$, it needed $50 \mathrm{~h}$ for benzene of $0.0022 \mathrm{mg} \mathrm{L}^{-1}$ to be degraded to below the safe concentration, while it just needed $32 \mathrm{~h}$ when the reaction temperature was $35^{\circ} \mathrm{C}$. This may be explained as follows. First, the internal energy of benzene molecules increased with the rise of temperature and their irregular movement became fiercer, which made the cyclic process of benzene's adsorption and desorption on the surface of nano$\mathrm{TiO}_{2}$ much faster, but the adsorption rate and degradation rate were larger than that of desorption, so the concentration of benzene kept decreasing. Second, when the temperature 


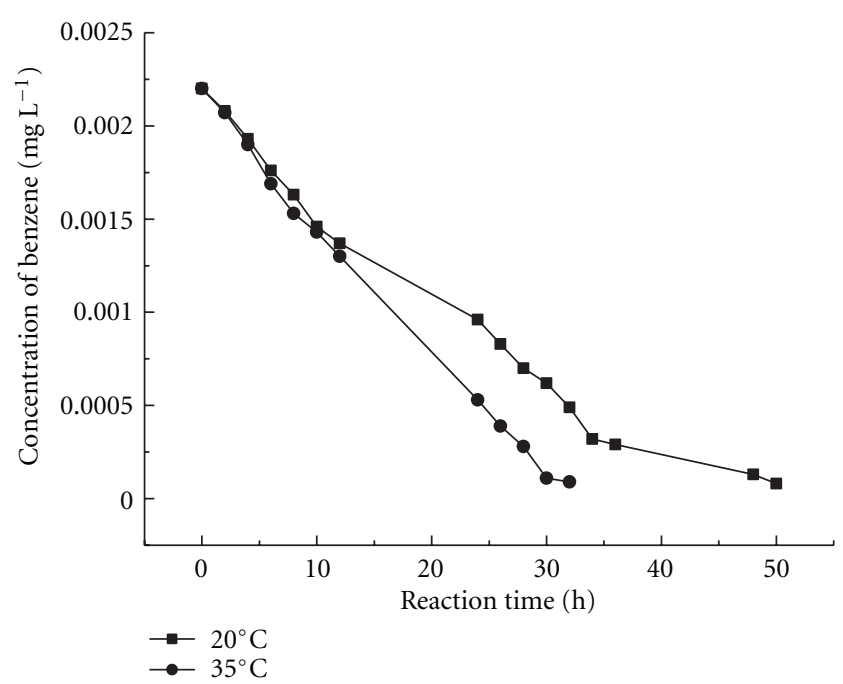

Figure 5: Effect of temperature on degradation of benzene by nano$\mathrm{TiO}_{2}$ immobilized on diatomite.

was high, the saturation vapor pressure of steam increased, which led to decrease of relative humidity in the reactor. In this case, the nano- $\mathrm{TiO}_{2}$ would release the steam and other dissolved gases adsorbed before to relieve the decrease of humidity. So the diatomite would adsorb more benzene and more benzene could be oxided to nontoxic gases by nano$\mathrm{TiO}_{2}$. While at low temperature, the benzene molecules were relatively steady and the rates of adsorption, degradation, and desorption were much slower, so the decrease rate of benzene's concentration at high temperature was relatively larger.

3.4. Effect of Light Intensity on Adsorption and Degradation of Benzene by $\mathrm{Nano-TiO} \mathrm{I}_{2}$ Immobilized on Diatomite. Light intensity is another factor which has important effect on degradation of benzene by nano- $\mathrm{TiO}_{2}$ immobilized on diatomite. As known, $\mathrm{TiO}_{2}$ can be activated by ultraviolet light. After being activated, the photogenerated electronics and holes will reduce or oxide the organics and inorganics adsorbed to the surface of the nano- $\mathrm{TiO}_{2}$. When the wavelength is definite, the intensity of the light will determine the number of electronics and holes generated by illumination, thus determining the concentration of benzene degraded by $\mathrm{TiO}_{2}$. It is the same for ultraviolet in visible light. Besides, as the light intensity at every point in the light range is different for different light source and different light space, so average light intensity is used as the intensity in certain space. According to the following formula [22]:

$$
E_{\mathrm{av}}=\frac{N \times \Phi_{s} \times U \times K}{A},
$$

$E_{\mathrm{av}}$ —average light intensity, Lx; $N$-number of fluorescent lamp; $\Phi_{s}$-light flux of a fluorescent lamp, Lm; $U$-use coefficient, generally $0.4 ; \mathrm{K}$-maintenance coefficient, 0.8 ; $A$-Incubator's bottom surface area, $0.2 \mathrm{~m}^{2}$ the average light intensity with different number of fluorescent lamp is listed in Table 2.

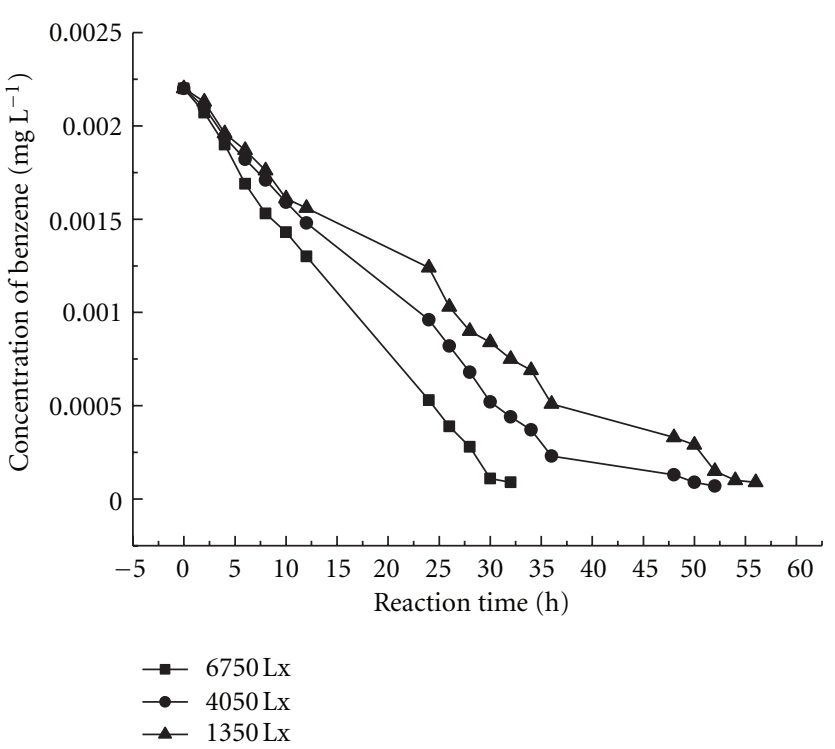

FIGURE 6: Effect of light intensity on degradation of benzene by nano- $\mathrm{TiO}_{2}$ immobilized on diatomite.

TABLE 2: The average light intensity for different number of lamp.

\begin{tabular}{lc}
\hline$N$ (number of lamps) & $E_{\mathrm{av}}(\mathrm{Lx})$ \\
\hline 1 & 1350 \\
3 & 4050 \\
5 & 6750 \\
\hline
\end{tabular}

The changes of benzene's concentration at different light intensity are shown in Figure 6.

It can be found that when the light intensity was definite, the concentration of benzene decreased with time going on. For example, when the light intensity was $4050 \mathrm{Lx}$, the concentration of benzene reduced sharply at the first $35 \mathrm{~h}$, while the rate became much smaller after that; this was also because at the first $35 \mathrm{~h}$, the adsorption rate and the degradation rate were much greater than the desorption rate, so decrease of benzene's concentration was significant, with time increasing, the desorption of benzene from the surface of photocatalyst gradually became apparent, causing the decrease rate of benzene's concentration become small. Besides, it can be seen that the stronger the light intensity was, the larger the decrease rate of benzene was. When the light intensity was $6750 \mathrm{Lx}$ it just needed $30 \mathrm{~h}$ for benzene to be degraded to below the safe concentration, while it cost more than $30 \mathrm{~h}$ when the light intensity was $1350 \mathrm{Lx}$ and $4050 \mathrm{Lx}$. This was because more holes were generated at large light intensity than at small light intensity, leading to faster degradation of benzene.

3.5. Effect of Relative Humidity on Adsorption and Degra-

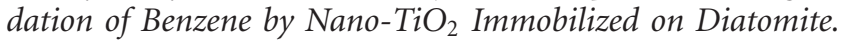
Relative humidity is also an effect which has important impact on degradation of benzene. In this section, the standard solution of $0.27 \mathrm{~mL}$ was first injected into the reactor, implying the water's volume was $0.27 \mathrm{~mL}$. To realize 
TABLE 3: Volume of deionized water needed to be added at different relative humidity.

\begin{tabular}{lc}
\hline Relative humidity $(\%)$ & Volume of deionized water $(\mathrm{mL})$ \\
\hline 50 & 0.110 \\
60 & 0.132 \\
70 & 0.154 \\
80 & 0.176 \\
\hline
\end{tabular}

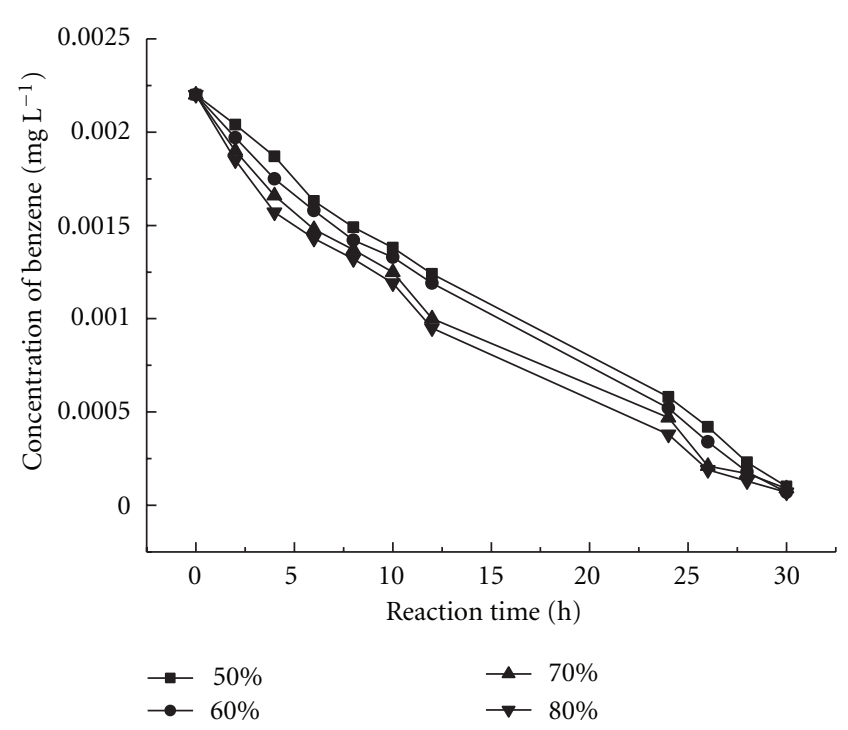

FIGURE 7: Effect of relative humidity on degradation of benzene by nano- $\mathrm{TiO}_{2}$ immobilized on diatomite.

relative humidity of $50 \%, 60 \%, 70 \%$, and $80 \%$, the volumes of deionized water needed to be added into the reactor were calculated according to gas state equation when the temperature was $35^{\circ} \mathrm{C}$. The results are listed in Table 3 .

Figure 7 shows the changes of benzene's concentration with reaction time under different relative humidity.

As is known, when the photogenerated holes transfer to the surface of $\mathrm{TiO}_{2}$, they can accept electrons from $\mathrm{O}_{2}$ and $\mathrm{H}_{2} \mathrm{O}$ to generate ${ }^{\bullet} \mathrm{O}^{2-}$ and ${ }^{\bullet} \mathrm{OH}$, which have strong oxidation ability. Undoubtedly, the more $\mathrm{H}_{2} \mathrm{O}$ there is, the more free radical there can produce. So it is beneficial for degradation of benzene when the relative humidity increases. It can also be found from Figure 7 that the degradation rate of benzene increased with the relative humidity ranging from $50 \%$ to $80 \%$. But it is not to say the relative humidity can be infinite. In practice, there is certain range of humidity for people to endure, about $40 \%$ to $70 \%$. So for degradation of benzene, the principle is the bigger the relative humidity is, the better the effect is, but people's comfort is the first to be considered.

\subsection{Effect of Benzene's Initial Concentration on Adsorption} and Degradation of Benzene by Nano- $\mathrm{TiO}_{2}$ Immobilized on Diatomite. When benzene's initial concentration is different, the degradation situation will be quite different. To verify effect of initial concentration on the degradation of benzene by nano- $\mathrm{TiO}_{2}$ immobilized on diatomite, two groups of

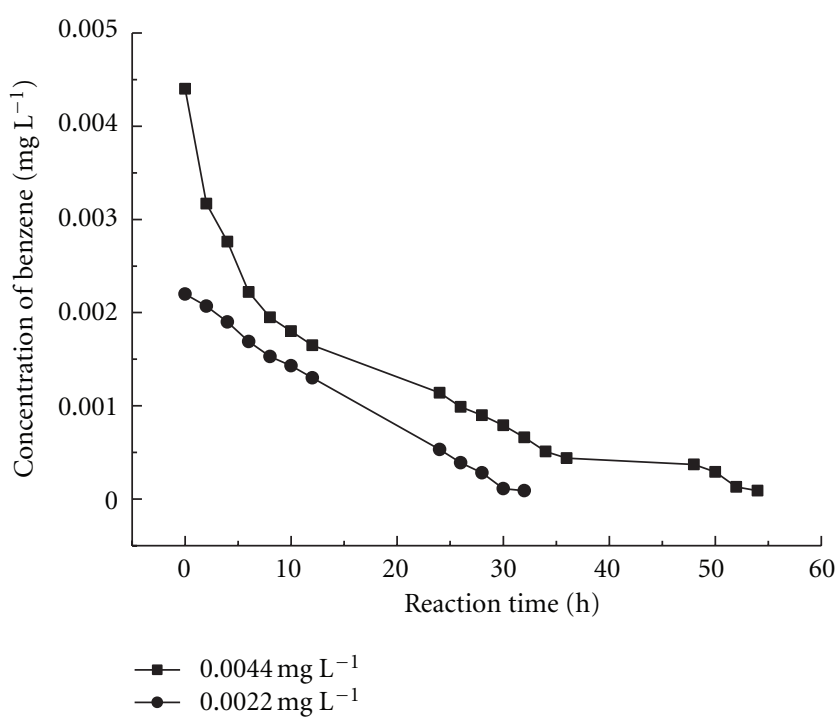

FIGURE 8: Effect of initial concentration on degradation of benzene by nano- $\mathrm{TiO}_{2}$ immobilized on diatomite.

experiments were carried out and the results are shown in Figure 8.

As Figure 8 shown, at first hours, the higher the initial concentration was, the larger the degradation rate was. This could be explained by degradation process of benzene by $\mathrm{TiO}_{2}$. First, benzene was adsorbed to the surface of $\mathrm{TiO}_{2}$. Second, it was oxided to nontoxic organics or even $\mathrm{CO}_{2}$ and $\mathrm{H}_{2} \mathrm{O}$. Third, the products were desorbed from the surface of $\mathrm{TiO}_{2}$. When the initial concentration of benzene was higher, there was more benzene adsorbed to the surface of $\mathrm{TiO}_{2}$, so the decrease rate of benzene was larger at first hours. But with time going on, the desorption of benzene from the surface of catalyst gradually appeared, which hampered the further adsorption and degradation of benzene, so the decrease rate of benzene's concentration became smaller. When initial concentration was $0.0022 \mathrm{mg} \mathrm{L}^{-1}$, it could decrease about $95 \%$ after $30 \mathrm{~h}$, which was higher than that of $\mathrm{Pd} / \mathrm{TiO}_{2}$ [11] in efficiency.

\section{Conclusions}

Diatomite can only adsorb benzene, while nano- $\mathrm{TiO}_{2} \mathrm{immo-}$ bilized on diatomite not only can adsorb benzene but also can degrade benzene to nontoxic organics. Experiments about effect of reaction conditions on adsorption and degradation of benzene by nano- $\mathrm{TiO}_{2}$ immobilized on diatomite showed that temperature had great effect on the adsorption and degradation process, when the initial concentration of benzene was $0.0022 \mathrm{mg} \mathrm{L}^{-1}$, it could be degraded to below the safe concentration by nano- $\mathrm{TiO}_{2}$ immobilized on diatomite after $30 \mathrm{~h}$ when temperature was $35^{\circ} \mathrm{C}$, while $50 \mathrm{~h}$ was needed when temperature was $20^{\circ} \mathrm{C}$. Light intensity was direct driving of the degradation process. $\mathrm{TiO}_{2}$ could not play role of degradation when there was no light, while it just needed $32 \mathrm{~h}$ to degrade benzene to below the safe concentration when light intensity was $6750 \mathrm{Lx}$. Relative 
humidity also impacted the degradation process. When relative humidity was $50 \%$, the concentration of benzene could reduce from $0.0022 \mathrm{mg} \mathrm{L}^{-1}$ to $0.0001 \mathrm{mg} \mathrm{L}^{-1}$ after $30 \mathrm{~h}$, but it could reduce to $0.00007 \mathrm{mg} \mathrm{L}^{-1}$ at humidity of $80 \%$. Besides, when initial concentration was $0.0022 \mathrm{mg} \mathrm{L}^{-1}$, it could decrease to below safe concentration after $30 \mathrm{~h}$, while the time was $54 \mathrm{~h}$ when initial concentration was $0.0044 \mathrm{mg} \mathrm{L}^{-1}$. In short, the nano- $\mathrm{TiO}_{2}$ immobilized on diatomite not only showed high adsorption and degradation capacity for benzene, but also could be used in decorative materials to remove benzene indoors conveniently.

\section{References}

[1] H. Masumoto, F. Kurisu, I. Kasuga et al., "Complete mineralization of benzene by a methanogenic enrichment culture and effect of putative metabolites on the degradation," Chemosphere, vol. 86, no. 8, pp. 822-828, 2012.

[2] J. Rakoczy, K. M. Schleinitz, N. Müller, H. H. Richnow, and C. Vogt, "Effects of hydrogen and acetate on benzene mineralisation under sulphate-reducing conditions," FEMS Microbiology Ecology, vol. 77, no. 2, pp. 238-247, 2011.

[3] C. Long, Y. Li, W. Yu et al., "Removal of benzene and methyl ethyl ketone vapor: comparison of hypercrosslinked polymeric adsorbent with activated carbon," Journal of Hazardous Materials, vol. 203-204, pp. 251-256, 2012.

[4] A. B. Ene, T. Archipov, and E. Roduner, "Competitive adsorption and interaction of benzene and oxygen on Cu/HZSM5 zeolites," Journal of Physical Chemistry C, vol. 115, no. 9, pp. 3688-3694, 2011.

[5] M. A. Lillo-Ródenas, D. Cazorla-Amorós, and A. LinaresSolano, "Benzene and toluene adsorption at low concentration on activated carbon fibres," Adsorption, vol. 17, no. 3, pp. 473$481,2011$.

[6] L. Serrano, I. Urruzola, D. Nemeth, K. Belafi-Bako, and J. Labidi, "Modified cellulose microfibrils as benzene adsorbent," Desalination, vol. 270, no. 1-3, pp. 143-150, 2011.

[7] M. Aivalioti, I. Vamvasakis, and E. Gidarakos, "BTEX and MTBE adsorption onto raw and thermally modified diatomite," Journal of Hazardous Materials, vol. 178, no. 1-3, pp. 136-143, 2010.

[8] S. Zuo and C. Qi, "Modification of $\mathrm{Co} / \mathrm{Al}_{2} \mathrm{O}_{3}$ with $\mathrm{Pd}$ and $\mathrm{Ce}$ and their effects on benzene oxidation," Catalysis Communications, vol. 15, no. 1, pp. 74-77, 2011.

[9] Q. Ye, J. Zhao, F. Huo et al., "Nanosized $\mathrm{Ag} / \alpha-\mathrm{MnO}_{2}$ catalysts highly active for the low-temperature oxidation of carbon monoxide and benzene," Catalysis Today, vol. 175, no. 1, pp. 603-609, 2011.

[10] W. Zhao, Y. Liu, L. Wang et al., "Catalytic combustion of benzene on the Pd/nanosize Al-HMS," Microporous and Mesoporous Materials, vol. 138, no. 1-3, pp. 215-220, 2011.

[11] J. B. Zhong, Y. Lu, W. D. Jiang et al., "Characterization and photocatalytic property of $\mathrm{Pd} / \mathrm{TiO}_{2}$ with the oxidation of gaseous benzene," Journal of Hazardous Materials, vol. 168, no. 2-3, pp. 1632-1635, 2009.

[12] T. D. Bui, A. Kimura, S. Higashida, S. Ikeda, and M. Matsumura, "Two routes for mineralizing benzene by $\mathrm{TiO}_{2}$ photocatalyzed reaction," Applied Catalysis B, vol. 107, no. 1-2, pp. 119-127, 2011.

[13] Y. Hu, D. Li, Y. Zheng et al., " $\mathrm{BiVO}_{4} / \mathrm{TiO}_{2}$ nanocrystalline heterostructure: a wide spectrum responsive photocatalyst towards the highly efficient decomposition of gaseous benzene," Applied Catalysis B, vol. 104, no. 1-2, pp. 30-36, 2011.

[14] Y. J. Xu, Y. Zhuang, and X. Fu, "New insight for enhanced photocatalytic activity of $\mathrm{TiO}_{2}$ by doping carbon nanotubes: a case study on degradation of benzene and methyl orange," Journal of Physical Chemistry C, vol. 114, no. 6, pp. 2669-2676, 2010.

[15] S. Liu, B. Liu, K. Nakata et al., "Electrospinning preparation and photocatalytic activity of porous $\mathrm{TiO}_{2}$ nanofibers," Journal of Nanomaterials, vol. 2012, Article ID 491927, 5 pages, 2012.

[16] Y. Dong, J. Chao, Z. Xie et al., "Highly ordered $\mathrm{TiO}_{2}$ macropore arrays as transparent photocatalysts," Journal of Nanomaterials, vol. 2012, Article ID 762510, 6 pages, 2012.

[17] G. Hong and C. Ma, "Photocatalytic degradation of indoor air pollutants by Pt-TiO ${ }_{2}$," Journal of Nanomaterials, vol. 2012, Article ID 405361, 5 pages, 2012.

[18] Y. Han, H. S. Kim, and H. Kim, "Relationship between synthesis conditions and photocatalytic activity of nanocrystalline $\mathrm{TiO}_{2}$," Journal of Nanomaterials, vol. 2012, Article ID 427453, 10 pages, 2012.

[19] C. Yu, The Study on Preparation of Nanosized $\mathrm{TiO}_{2}$ Immobilized to Diatomite Particles and Degradation Process of Formaldehyde, Tianjin University, Tianjin,China, 2007.

[20] C. L. Yu, Y. Kang, and W. Zhao, "Preparation of nano- $\mathrm{TiO}_{2}$ immobilized onto diatomite micro-particles," Nanotechnology and Precision Engineering, vol. 6, no. 4, pp. 254-260, 2008.

[21] C. Yu, H. Quan, and Y. Kang, "Experimental study on the formaldehyde degradation by nano- $\mathrm{TiO}_{2}$ immobilized on diatomite," Acta Scientiae Circumstaintiae, vol. 32, no. 1, pp. $1-6,2012$.

[22] H. Xiao, Electric Lighting Technology, chapter 5, China Machine Press, 2009. 

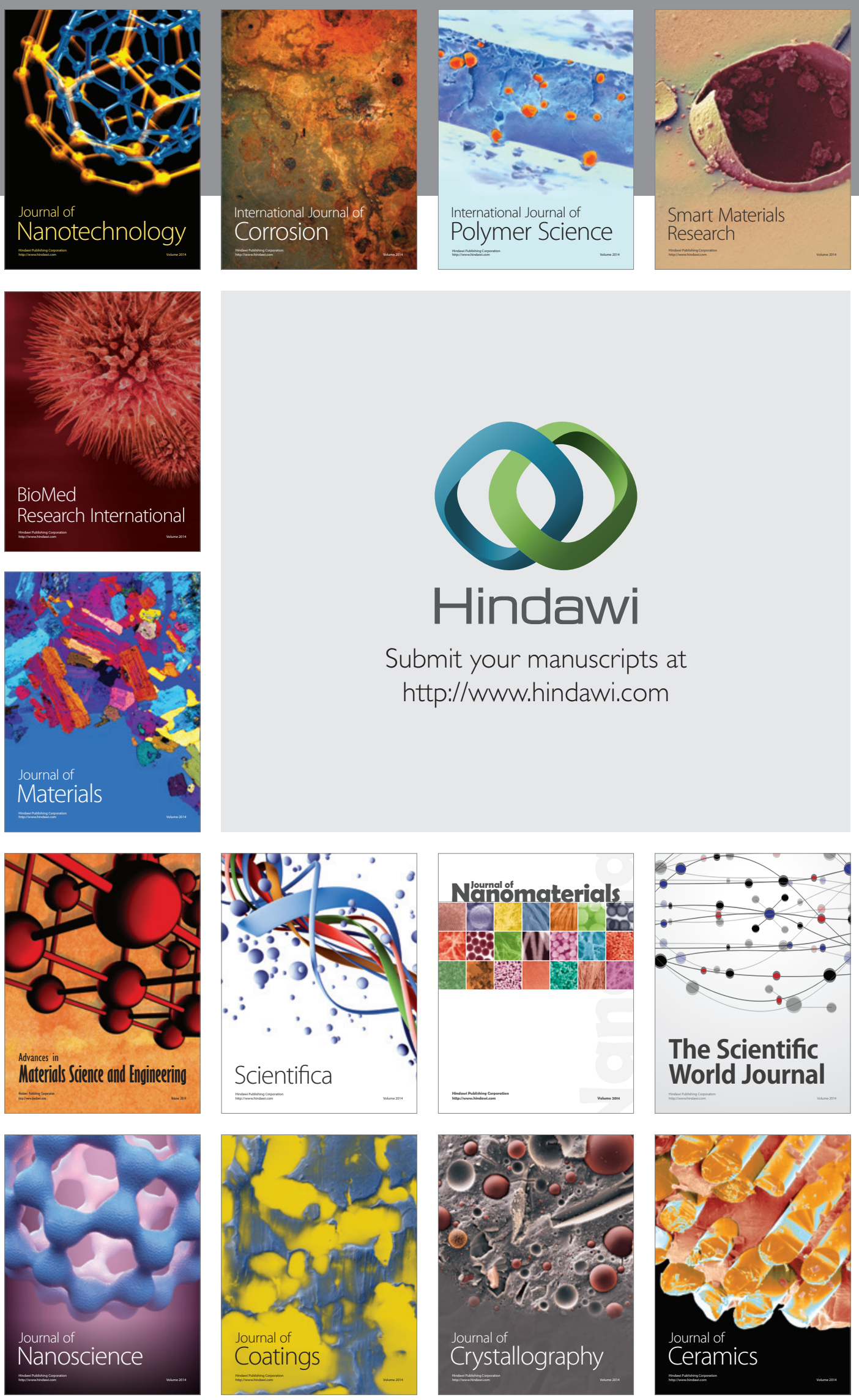

The Scientific World Journal

Submit your manuscripts at

http://www.hindawi.com

\section{World Journal}

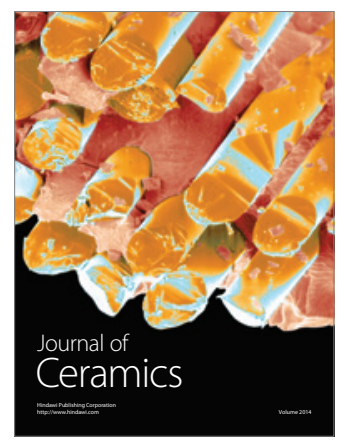

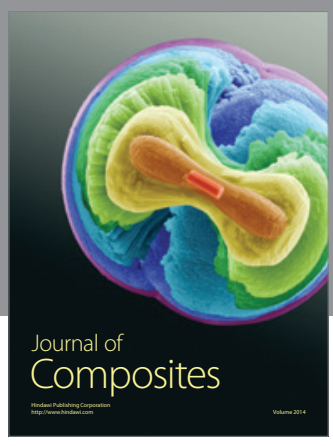
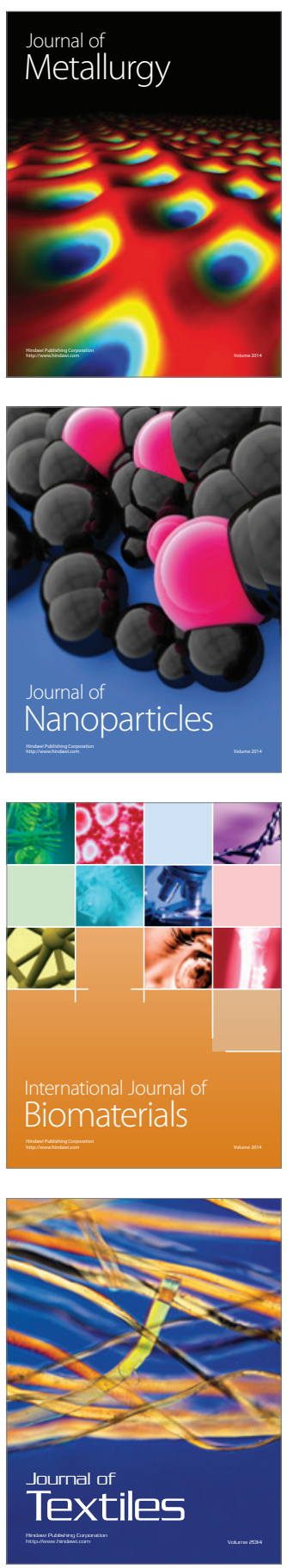